\title{
1. From the Theatre Scene to the World Scene: the Multiplicity of the Bodies. The Theatre Changes Lives
}

\author{
David Le Breton \\ doi.org/10.3280/oa-637-1
}

Emotional culture is not something like a lead blanket that weighs on individuals, it is not imposed like a mechanical fatality; it is more like an instruction booklet that is made available to them, a suggestion on how to respond to specific circumstances, and leaves space for advantageous strategies, for dissimulations. Individuals can "play" with the expression of their emotional states, feeling for example too far removed from those who appear to be socially adequate. If a friend's words disappoint them, they remain calm and quiet on the surface; they feel no pain at the death of a loved one, but try to look sad; they wish to draw compassion on their condition and display a tearful attitude; they try to seduce and adopt the finery of passion. Social situations are full of discrepancies between the inner feeling and what is shown on the outside. Individual sociological competencies include, naturally, a relative control of our emotions according to what one wants to show to others. If one falls short of the expectations of others, and gives importance to them, he can make up with some personal manoeuvre to the expression of his affectivity. The control of the image he wants to give to others enables him to manage or manipulate them, such as by preserving their esteem etc. By appearing to be feeling one emotion which he does not really feel, or by skilfully hiding his inner state, the individual builds his own character, thus meeting the expectations of his audience or he shows the identity he wishes to display. The expression of feelings is a show, a display, which changes according to different audiences and to what is at stake (Le Breton, 2016). For the anthropology of the actor, the theatre scene is a workshop where ordinary passions show themselves as a score of physical signs which are easily understood by the public as making sense. The actor dissipates his own identity into his character, even if the critics do not stop comparing different interpretations and evaluating the different performances they see of the same role in a repertoire. But the actor does not blend in with his character, he interprets it and supplies the audience with the signs necessary to make his role understood. He plays; that means that he puts some ludic distance between the passions aroused by his role and his own. He works like a craftsman on his own body to suppress his own individual emotional life and give 
an opportunity to his character's emotions on the stage. He builds the credibility of his role in front of his public thanks to the work of interpretation carried out with the director's help. The transmutation is possible only because passions are a product of a social and cultural construction, and they are expressed through a game of signs which are readily available to every individual, even if he does not feel them.

His composition is a work on himself, a subtle chiselling of his affectivity, gestures, movements and voice, producing the physical and moral rigour of the role. The feeling of the theatre is different from that of real life. The paradox of the actor consists in the art of employing his body and his voice in order to deploy at a set time a throaty hilarity for a line heard a thousand times or the agony of sorrow, or of jealousy. He can play with the same ease joy, pain, melancholy, simply by drawing from a social and cultural repertoire. He can be afflicted personally by bereavement or stricken by grief, but when he treads the boards, he merges with the rules of conduct of his character, and makes its psychology credible by turning into a sociologist who pays attention to his own bodily and oral expressions (Le Breton, 2016). On stage he can declare his passion to a colleague he detests, because he has to be like a goldsmith in the art of displaying feelings he does not feel and manufactures provisionally according to the needs of his role.

Today, given the resources at their disposal and the scale of their task, it is becoming difficult for teachers to invent new ways of freeing children from the routines of their suffering as much as from the pitfalls of their peer culture fed by marketing and conformism. The transmission is not only an instruction, but a way to impress a direction, and it requires some tools: dance, theatre, writing, travel, etc. These steps must engage the pupils, value their individuality, trust them, while the people in charge of the project must never duck the responsibility assumed towards a group or a student. The theatre is a detour to hold oneself in a different context, in front of a public who is not the same as in daily life, which requires pre-fixed roles; it is a different scene where one can reinvent oneself, can dismantle old references and discover the ease of becoming someone else. As it duplicates the individual, it frees him of the constraints of ordinary life, theatre is a tool for self-awareness, an opportunity to stand back from difficult situations, it makes it possible to face, on a different scene, confusing situations that might otherwise appear insoluble. If one plays a role on stage, if one can change roles, if a director asks an actor to play a character in a different way, that means that even in real life one can transform oneself, one can no longer be a prisoner of one's own roles. The theatre is a game played with the stuff of which the social bonds are made, a way to undo them and make them up again differently. The border dividing the scene and the audience in the 
theatre is symbolic. There are invisible but powerful to-ings and fro-ings. There are multiple resonances between actor and spectator. The relationship is not one-way. The spectator is touched as well, and even changed by the representation, although I am not going to speak of this any further on this occasion.

In a conversation with the philosopher George Steiner, Cécile Ladjali mentions her work with the pupils of a high school in the suburbs of Paris. She asks them to write poetry, which will be later published, and to write a theatre play partly inspired by Sophocles' Oedipus the King. Tohu-Bohuis is precisely a work revolving around the myth of Babel, an indirect way to question them about their cultural and linguistic diversity. The fact that the first hurdle to conquer is their resistance to poetry, which for them, especially the boys, rhymes with "shame", and is a "girly" and despicable activity, is extremely symbolic. However, in due time, she conquers their resistance and the texts are written and read, the play staged:

they were astonished by the beauty of their text. [...] They were almost ashamed to present their text in the library at the end of the year, but afterwards they became very proud. They made progress, they aged three years in the space of two hours. They matured very quickly (Steiner and Ladjali, 2003, p. 63 and p. 78).

Beyond the stereotypes, some pedagogical experiences are opportunities for revelations, for an initiation journey.

In the movie L'esquive (2003, English version Games of Love and Chance), by Abdellatif Kechiche, a teacher of French helps her students from a suburban area of Lille to stage Marivaux's play Le Jeu de l'amour et du hasard. They speak at full speed without ever listening to each other. Their words are tirelessly stuffed with swearing like «son of a $*$ » or «mother*», even girls cannot escape it. However, when they start using Marivaux's language, they start listening to each other, they speak slowly and savour the words with pleasure. During rehearsals, they repeat the lines with respect for each other. The theatre is a symbolic place where putting oneself to the test under the eyes of the others is a way to become detached from oneself and reflect on language and the relationship with others and with time. On stage, one can redeem oneself. A theatre workshop inspired by these principles offers to young people, for example, the opportunity to experiment with different characters, a thing typical of adolescence, but conducted here far from any identification with consumer goods and with social network identities. Here there are characters loaded with meaning and moved by a common project, in a clean break with the rituals of the city. The youngsters show unexpected facets, they are shaken from their ties, they break out of 
their routine of language and behaviour and they discover with wonder that other relationships are possible in their world, infinitely calmer, happier, at the heart of a sociability that no longer involves continuous blustering and aggressiveness. The theatre reveals to them that one is never a prisoner of oneself, nor of social roles that seem to stick to the skin. Playing these characters, they feel good and safe from the roles taken on forcibly to safeguard their reputation in the streets. They change their framework, redefine their relationships with others and experience a true renaissance.

Dance can also play a similar role as shown by the atelier opened by Pina Bausch in Wuppertal with high school students; forty-six pupils aged between fourteen and seventeen from fifteen different local schools, with different social and cultural origins. For nearly a year, two dancers from the Tanztheater troupe lead the work of the pupils on one of Bausch's choreographies, Kontakthof (2000). Bausch herself regularly supervises the project. Thanks to two hours of work every Saturday for everyone, with five to eight hours for the leading roles, the students get into the part and are deeply transformed. The first sequences are moving, notably when touching the bodies of others is required: laughing out loud, being shy, or incapable of performing a task... The movements are incongruous, clumsy, carried out with a faint smile to show that they are not fools. Little by little a taming takes place, and it feeds the ease of the interaction with the others on the stage. Those who had problems with their bodies and found it difficult to interact with members of the other sex, are freed of their preconceptions. A space of trust is created under the eyes of the dancers, where the emotions can circulate, and self-confidence and reciprocal confidence are established. At the end of the show, they all agree that the experience has freed them and opened them to others. Several of the adolescents with difficult backgrounds have been able to find renewed self-confidence and a power of expression that they did not have before. A girl explains that her family is struggling since her father was killed two years previously in the explosion of a gas bottle. She thinks often of him and believes he would have been proud of seeing her dancing like that.

In a work written in the first person, the American writer David Vann reconstructs the development of Steve Kazmierczak, who killed five pupils and wounded eighteen before committing suicide at the North Carolina University on St. Valentine's day 2008. The writer, who did not have a happy childhood, has a profile similar to Kazmierczak's, and asks himself why he did not turn into a killer. "Why had I not ended up hurting anyone? How had I escaped, and why hadn't he?» (Vann, 2011, p. 3). Vann remembers when as an adolescent he used to stay awake and hide in the grass with a Magnum 300 which he had received from his father and aim at the faces of passers-by 
through the rifle scope. Despite the sensation of power he could feel in those moments, he was able to resist the temptation and he just shot the streetlights to unload the anger which was devouring him. He was harassed by the other pupils because of his appearance, his clumsiness with girls, and his refusal to drink. The fact that he was good at school was also a cause for resentment from the others. His father's suicide affected him deeply. $\mathrm{He}$ remembers every day of his childhood as humiliating: he felt threatened at every break when the class gathered and sought safety in isolation until one day a friend took him to the after-school drama workshop. During the trial, when he was asked to speak about himself, for the first time, instead of saying that his father had died of cancer as he usually did, he mastered his emotions and spoke about his father's suicide. He was surprised to be accepted unreservedly by the group.

What it meant for the shape of my life was that instead of continuing to spiral down into a double life, things began to improve for me, and this is what never happened for Steve in high school. His life spiraled into drugs, medications, suicide attempts, sexual shame, bitter fights with his mother, threats of violence (ibid., p. 21).

The theatre was for Vann a great escape from a position of victim, a way to remain the actor of his existence.

The workshop session and the moment of the performance are matrices of expression, a way to experiment with the alterity within oneself and to feel that one is not a prisoner of one's own roles in life, and that it is therefore possible to transform oneself beyond the pleasure of playing and of receiving the public's applause. For people who often find themselves in an awkward position with social relationships and whose life is often subjected to the direction and appreciation of others, these are moments of triumph. For once, they are listened to, and even glorified by public applause. The workshop is where this work is carried out, the performance is sometimes uncertain from the spectator's point of view, each population requires a different support system, the theatre with young psychotics is not the same as that with young people affected by Down syndrome, with elderly people with personality disorders, or with young people in distress or immersed in delinquency.

For the person on stage, whether a pupil in a school, a young person or adult in distress or having behavioural problems, labelled as mentally ill or mentally handicapped, or suffering from Down syndrome, theatre is a temporary way out of oneself, surrounded by partners and an audience who enhance the resources for change induced by the situation. The theatre, in all its manifestations, is an experience of the space in a specific time with elements of the social bond as raw material. It enables the actor, regardless 
of who he or she is, to disappear from his or her specific identity, from his or her individual, social and cultural responsibilities. He gets rid of himself and gets into a game between the character he is impersonating on stage and the person he is in real life. He takes a temporary holiday from himself, but without losing himself (Le Breton, 2015). He is in a position of reflection, in the figurative and literal sense. He feels himself, he puts himself to the test, he discovers he is in connection with others on the stage. He sheds his character from real life, without forgetting it, but putting it into imaginary brackets in order to explore universes different from the familiar one. The public is not there to correct him, or to put him back into his place, or give him lessons. During the time of the play, the actor is in the transparency of his role, immunised from the judgement of others. He finds himself in what Winnicott calls the «intermediate area of experience» without having the sanction of reality, he escapes outside social conventions and any judgement towards him. He can be transformed by this experience. This is why it is used in psychodrama, sociodrama, role play, theatre forums, etc. The theatre ritual protects and gives authority to perform gestures, words and actions that would be out of place in real life. The role is like an envelope of sense which protects and authorises the demise of one's system of defence. Actors become different from who they are ordinarily.

Whether these forms of theatre aim to transmit something, to care for someone, to give pleasure, to encourage reflection, they provide an opportunity for expression, pleasure and recognition. The scene induces effects of metamorphosis on the populations who are seeking something other in their existence, the scene pulls them out of their fragility zone. 